\title{
Enhancing the Performance of Reverse Power Relay for Generator Protection
}

\author{
DEBANI PRASAD MISHRA ${ }^{1}$, RUDRANARAYAN SENAPATI ${ }^{2}$, SUMAN PATRA $^{3}$, \\ BIMALENDU MISHRA ${ }^{4}$, ANANYA APRAMEYA ${ }^{5}$, \\ ${ }^{1,3,4}$ Department of Electrical and Electronics Engineering, IIIT, Bhubaneswar, Odisha, INDIA \\ ${ }^{5}$ Department of Computer Science Engineering, IIIT, Bhubaneswar, Odisha, INDIA \\ ${ }^{2}$ School of Electrical Engineering KIIT Deemed to be University, Patia, Bhubaneswar, INDIA
}

\begin{abstract}
The generator is the most important component in energy generation, and it needs to be protected from both internal and external disturbance. Reverse power relays (RPR), with the directional relay being the most commonly utilized as the principal safeguard, are used to trip the turbine generators to minimize the damage of prime mover. Modeling tools are helpful for learning the basics of a power system, especially for newbie engineers. These tools assist novice engineers in modulating the system in both normal and abnormal situations. This paper demonstrates how to model and simulate a digital RPR on MATLAB. Different conversions of data processes involved in signal digitization are also explored. Electromechanical relays were previously popular, but fast and very accurate digital relays have now surpassed them. Fast relay functioning is recommended, especially in the case of system faults that might cause a blackout. Digital relays provide a number of advantages, including several changeable settings and a small size. The performance of test relay in this article is tested by connecting a synchronous generator of $11 \mathrm{kV}$ to $220 \mathrm{kV}$ via a step-up transformer.
\end{abstract}

Key-Words: - Reverse Power Relay, Relay Modeling, Digital Relay, Fault, Generator, Protection System

Received: May 15, 2021. Revised: November 29, 2021. Accepted: December 16, 2021. Published: December 28, 2021.

\section{Introduction}

This paper intended to introduce a digital reverse power relay (RPR) model that balances system performance identification with cost and flexibility. Variation of testing settings and relay's design can be considered for this model. A simple technique is employed to finish the tasks depending on the objective function under the constraints that works well for a variety of measurement and performance. A digital reverse power relay's functionality is briefly described, as well as how it may be used in the electrical power industry.

\section{Literature Review}

A unique flux-based approach for protecting synchronous generators from out-of-step. Out-ofphase conditions are discovered by analyzing the measured data like acceleration and angular velocity from the generator's magnetic flux at relay's site. Outof-step occurs when the angular acceleration's polarity changes from negative to positive and also the angular velocity exceeds base angular velocity [1]. The problem of DG (Distributed Generator) islanding occurs in networks where islanding is disallowed. Automatic network operations decide how long DGs left in islanding mode must be disconnected [2]. The vulnerability of small-scale synchronous generators to system failures as well as their dynamic behavior are explored [3]. A new way for identifying Loss of Excitation issues in hydro electric generators has been developed by a versatile neural fuzzy inference system [4].

To carry out Photovoltaic Distributed Generation (PV-DG) in dissemination organizations, answers for changing present defensive strategies and converse power hand-off (RPR) usefulness against bi-directional power stream should be researched. A converse power stream circumstance is shown in the MATLAB plan of a $100 \mathrm{~kW}$ PV-DG associated with the framework, and various appropriation network working conditions are examined [5]. After an intensive assessment of these variables, a dependable voltage drop expectation model is given. For a particular low-medium evaluated creating framework in the $400 \mathrm{kVA}$ power range, the model is approved by limited component investigation and exploratory discoveries [6]. Under defective conditions, the opposite power hand-off separates the 
DG from the appropriation organization, forestalling a converse force in the organization. It likewise works out the opposite power and prescribes the suitable change worth to give an answer for shield the dispersion network dependent on transfer settings and appropriation framework changes [7]. Electromechanical relays were once broad, yet they have since been displaced with high-precision, high velocity advanced relays. Quick hand-off working is significant, particularly for issues that may bring about a framework power outage [8]. A definitive reference for administrators and reviewers of enormous utility and modern producing offices who manage a few units of changing size, provenance, and vintage is Operation and Maintenance of Large Turbo-Generators. It contains far-reaching data on the activity and support of a wide range of turbinedriven generators produced across the world [9]. Outof-step, loss-of-excitation, reverse power, external fault, and other protective relay techniques mentioned in relay instruction manuals address common conditions and may not be applicable in all cases [10]. The framework's displaying and upgraded turn around power insurance work were assembled and tried utilizing the model to trip the machine in a sensible measure of time after such an episode [11]. A strategy is introduced for evaluating the hand-off response to the applicable stage turn and other expected elements. It is shown that stage turn has little impact on zero-grouping captivated relays [12]. The stated method examines acceleration and angular velocity data acquired in machine stator terminals calculated magnetic flux [13]. A remarkable versatile distance work for coordinated generator loss of excitation (LOE) assurance has been created within the sight of Static Synchronous Compensator (STATCOM). The Berdy distance work is by and by the frequently utilized LOE issue aversion strategy [14].

Another strategy for distinguishing loss of excitation in simultaneous generators that doesn't need any settings. In contrast to the customary framework, which requires exhausting work to design the relays, the proposed technique doesn't require any activity limit [15]. In case of synchronous generators LOE is identified utilizing this methodology. The procedure depends on the idea of a period space advanced stage examination [16]. To build up a solid methodology for Loss of field (LOF) security in synchronous generators, numerous electrical amounts of generator are investigated, considering terminal voltage $(\mathrm{V})$, dynamic $(\mathrm{P})$, flow $(\mathrm{I})$, responsive force $(\mathrm{Q})$, and also the force point $(\delta)$ changes [17-18]. The objective is to check and build up the reasons for a mal-outing or inability to trip the defensive transfers; a numerical model in the MATLAB Simulink programming climate is utilized to represent the suggested symphonious twisting cure [19].

In contrasted with the notable Fourier and Cosine channels, the second-request Taylor-KalmanFourier channel improves the consistent state and transient reactions of the transfer [20]. One of the primary contributors to high voltage insulation deterioration is partial discharge (PD). For early detection, an internet monitoring system has been proposed [21]. To decide the fault bearing, an averaging channel is utilized to work out the correlation coefficient of gradual voltage and current [22]. One of the most significant consequences of DG is RPF, that occurs whenever the production of a distributed electric power plant is exceeded in comparison to the local load demand, this causes electricity to flow in another direction than typical [23]. An extraordinary wellbeing answer for spiral circulation frameworks with (disseminated age) DG without the prerequisite for correspondence support, outfitted with time current voltage double setting directional overcurrent transfers [24]. Advanced transfers have extra advantages, like numerous alterable settings and a little size. The transfer execution is assessed in this article utilizing a $11 \mathrm{kV}$ coordinated generator coupled to $220 \mathrm{kV}$ through a move forward transformer [25]. Protection relays are important components in distribution networks because they safeguard against interphase and singlephase-to-ground failures [26]. The working season of assurance transfers has become a key problem with entry of renewable energy sources based distributed generation (RES-DG) into distribution network (DN) to avoid RES-DG mis-coordination and annoyance stumbling [27]. The overcurrent transfer (OCR) may breakdown because of the opposite directional shortcoming current instigated by the association of DGs in the power circulation framework [28]. The discrete Teager energy (DTE) is assessed utilizing an internet-based Hilbert-Huang change dependent on the principal characteristic mode work obtained from the disintegration of current signs from the two closures of the transmission framework, handled utilizing an outfit exact mode deterioration approach [29]. The execution of the shortcoming current stream course will work with the establishment of a touchy voltage energized ground issue assurance hand-off for HRG (High Resistance Ground) [30].

\section{Problem Formulation}

To detect the synchronous generator's motoring activity, RPR are extensively utilized in power systems. Whenever the prime mover (turbine or 
motor) fails, but field winding is yet coupled to excitation system, circumstances like this arises. As a result, the machine takes on the characteristics of a syn. motor coupled to huge power grid. In this case, turbines become the machine's active load. Motoring action depletes the system's power to drive the concerned prime mover, which can result in serious damage to it. In the case of a steam turbine, this state is not ideal, and there is an unfavourable temperature rise. As a result, such circumstances must be detected immediately, and the Generator Circuit Breakers (GCB) must be triggered. Unburned fuel can create a fire or explosion, even though gas turbines and diesel engines being less prone to immediate injury.

\begin{tabular}{|c|c|c|c|}
\hline $\begin{array}{l}\text { Prime } \\
\text { Mover }\end{array}$ & $\begin{array}{l}\text { Motor } \\
\text { Propulsion } \\
\text { (Percent of } \\
\text { rated) }\end{array}$ & $\begin{array}{l}\text { Damage that } \\
\text { might occur }\end{array}$ & $\begin{array}{l}\text { Security } \\
\text { Setting }\end{array}$ \\
\hline \multirow[t]{2}{*}{$\begin{array}{l}\text { Engine } \\
\text { run by } \\
\text { diesel }\end{array}$} & \multirow[t]{2}{*}{$5-25$} & $\begin{array}{l}\text { Explosion } \\
\text { caused by } \\
\text { Unburned } \\
\text { fuel }\end{array}$ & \multirow{9}{*}{$\begin{array}{l}50 \\
\text { percent of } \\
\text { driving }\end{array}$} \\
\hline & & $\begin{array}{l}\text { Gearbox/shaft } \\
\text { damage }\end{array}$ & \\
\hline \multirow[t]{2}{*}{$\begin{array}{l}\text { Turbine } \\
\text { (gas) }\end{array}$} & $\begin{array}{l}\text { Split: } 10.0- \\
15.0\end{array}$ & \multirow[t]{2}{*}{$\begin{array}{l}\text { Damage to } \\
\text { the gearbox }\end{array}$} & \\
\hline & $\begin{array}{l}\text { Single: } \\
>50 \%\end{array}$ & & \\
\hline \multirow{2}{*}{$\begin{array}{l}\text { Turbine } \\
\text { (hydro) }\end{array}$} & $0.2-2.0$ & \multirow{2}{*}{$\begin{array}{l}\text { Cavitation in } \\
\text { the blade and } \\
\text { runner }\end{array}$} & \\
\hline & $>2.0$ & & \\
\hline \multirow[t]{3}{*}{$\begin{array}{l}\text { Turbine } \\
\text { (steam) }\end{array}$} & \multirow[t]{3}{*}{$0.5-6.0$} & $\begin{array}{l}\text { Damage to } \\
\text { turbine blades }\end{array}$ & \\
\hline & & $\begin{array}{l}\text { Explosion } \\
\text { caused by an } \\
\text { increase in } \\
\text { steam } \\
\text { temperature }\end{array}$ & \\
\hline & & $\begin{array}{l}\text { Damage to } \\
\text { geared sets' } \\
\text { gearboxes }\end{array}$ & \\
\hline
\end{tabular}

Table 1 shows the potential issues associated with various prime mover types. The reverse power relay is often set at $0.2-0.5$ of the prime mover's driving capabilities. The power needed by generator to drive primary mover at a given rpm is referred to as "motoring power." The primary mover's manufacturer usually provides this information.

\section{Problem Solution}

A reverse power scenario can occur when the machine's frequency is to be synchronised is scarcely lower than the frequency of the bus bar and the breaker in closed state during synchronisation. Power flows from bus bar to machine in this situation. As a result, the incoming machine's synchronisation frequency is somewhat higher than bus bars. It makes sure the machine to start working immediately as the circuit breaker is turned off. Reverse power relay might potentially use to identify islanding.

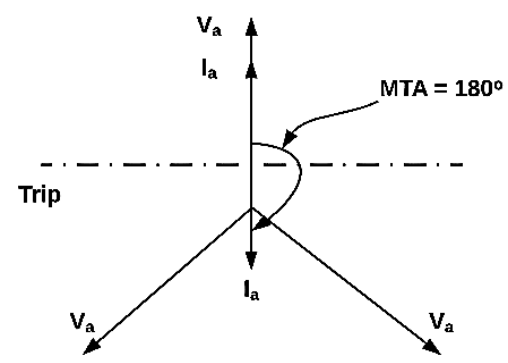

Figure 1. (a) Representation of Phasors Power Flow

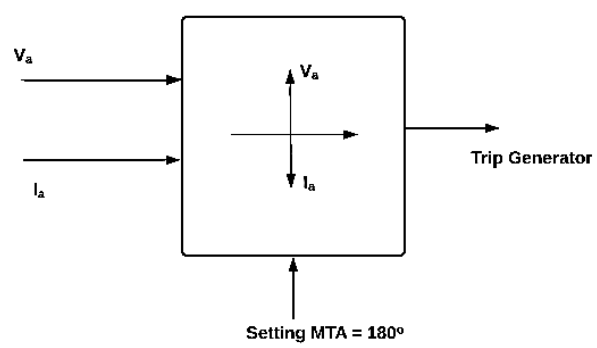

Figure 1. (b)Representation of Current and Voltage Block in Reverse

A RPR is a directed relay that monitors the flow of power from the generator and takes necessary action if there is an abnormal condition. Power is switched from bus bar to generator in abnormal circumstances. When the primary mover fails, this circumstance is common. When compared to the generator rating, the actual power consumed from the grid is relatively minimal. As illustrated in Figure 1, the current through the stator, on the other hand, experiences a 180 " phase change, which is known as the Maximum Torque Angle (MTA). This implies if we employ 
directional relays with a Maximum Torque Angle of 180 ", loss caused to prime mover will be detected as current phasor will reach and reverse the concerned trip area. However, whenever compared with forward current, size of reversed current phasor will be relatively modest since the generator only pulls enough actual power to operate the turbine and satisfy losses caused.

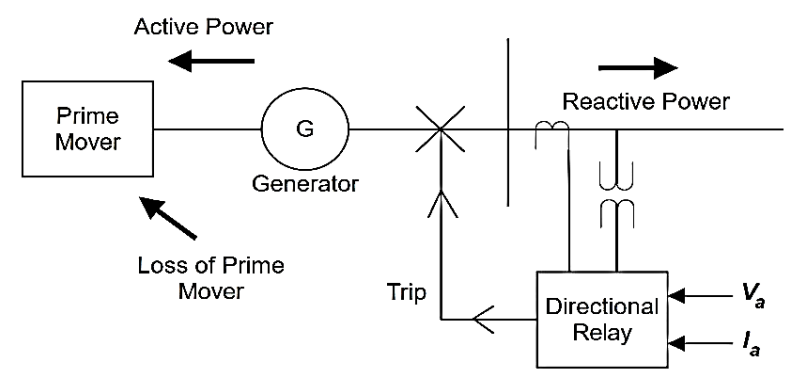

Figure 2. RPR in a Power System

Figure 2 depicts the RPR installation on a power supply. To minimise erroneous protection behaviour caused by Current Transfer (CT) phase angle errors, metering class is required to be placed. whenever a generator supplies a considerable quantity of reactive power near to 0 power-factor. The RPR is split into three components to simulate the reverse power relay: a directing element, a delay element, and a hold block.

A. Directional Relay: Current and voltage signals from the Current and Potential Transforms are transformed to a perfect square wave shape with one directional element value. After that, product of 2 level signals is done to give outputs of ' 1 ' and ' -1 ' as overlapping and non- overlapping intervals respectively. The overlapping interval is ' +1 ', whereas the non-overlapping interval is '- 1 '. After that, Integration is done to the product with limits as 0 to '-L'. Integrator's limit is taken as ' 0 ', ensuring that it is always less than 0 under typical load flow circumstances. The integral output, on the other hand, tends to decline under reversed power flow conditions till it hits a threshold value of ' $L$ '. In this example, $\mathrm{L}$ is taken as 0.01 , however any value could be selected depending on the amount of reverse power.
B. Delay Element: The output of directional element (input of delay element) is routed to decision block, which outputs ' 0 ' to indicate normal conditions, ' 1 ' to indicate abnormal situations (reverse power situations). Output generated is then integrated. The value of Integral is compared to value of ' $\mathrm{T}$ ' (threshold level), which is set equal to the value of delay time. Whenever integral output is smaller than level $\mathrm{T}$, the delay element's output is 1 , indicating normal operation. Since the integrator's input is ' 0 ,' the system is in a stable state. As a result, the integrator's value should be ' 0 ' (smaller to value of 'T'), and delay element's output will always be 1 . However, in the event of a permanent abnormal state, the integrator's input is ' 1 ', and the integral value surpasses $\mathrm{T}$ after ' $\mathrm{T}$ ' seconds, forcing delay element give a ' 0 ' as the output, indicating a fault condition. If a transient situation or temporary fault lasts shorter to ' $\mathrm{T}$ ' seconds, relational operator resets the integrator as ' 0 ' after the fault disappears.

C. Hold Block: This block's function is to maintain the relay's state as steady after it trips. As the fault will no longer exist once the Circuit Breaker (CB)t has opened, the relay will be tempted to direct a signal with ' 1 ' to $\mathrm{CB}$, leading to close once more. The delay block's ' 0 ' value is first inverted, then integrated. This block's o/p will change from ' 1 ' to ' 0 ' as soon as the integral value surpasses the ' 0 ' value. However, because the integrator cannot be reset, if integral reaches the threshold ' 0 ,' then it would not return to the previous value, this hold block's output will be ' 0 ' every time. Switch block, which is located in the hold and delay elements, is solely required in preventing relay from being falsely tripped in the course of first transient's phase.

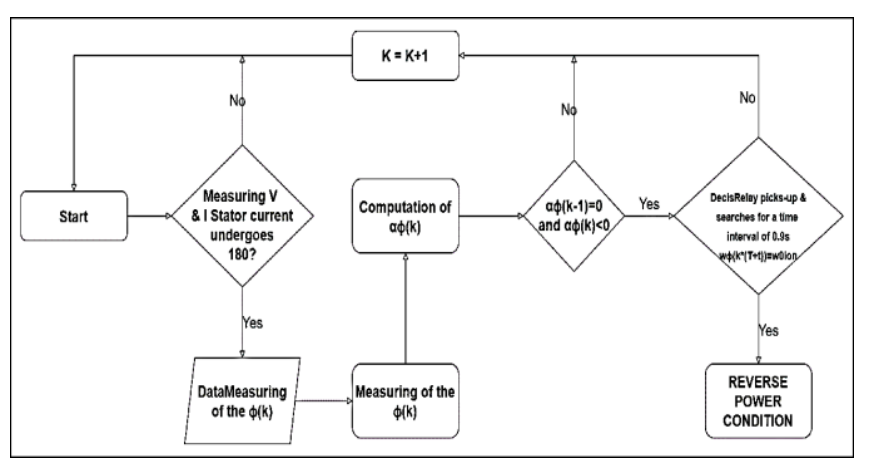

Figure 3. Flowchart diagram of the proposed relay 
Following reverse power, the stator current in generator undergoes a phase shift of $180^{\circ}$, the MTA. However, as previously indicated, the angle fluctuates through $90^{\circ}$ and $90^{\circ}$ in response to load increase and there's a planned drop in the generator's mechanical input. Configurations of these traditional reverse power relay and the suggested flux-based approach for better comparison. In addition, Figure 3 depicts the suggested scheme's flowchart diagram.

\section{Simulation and Results}

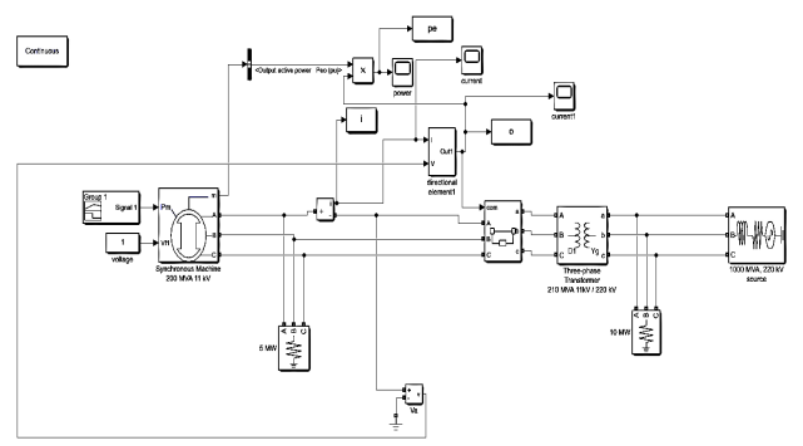

Figure 4. Simulation Model of RPR in Power System

The recommended hand-off is tried and simulated utilizing a $200 \mathrm{MVA} 11 \mathrm{kV}$ simultaneous machine, which is associated with the $220 \mathrm{kV}$ organization through a move forward transformer $11 / 220 \mathrm{kV}$ as displayed in Figure 4. The relay is put through its paces in a variety of circumstances. The following are the test circumstances, results, and discussions.

\section{CASE-1:}

Inside 20 seconds, the mechanical contribution to the generator shifts from 0.2 to $0.8 \mathrm{pu}$, which is a run of the mill situation. Figure 5 (a)depicts the noticed info/yield power and (b)relay state. The transfer doesn't trip in this occurrence, however, the $\mathrm{o} / \mathrm{p}$ power sways about the balance point from the start.
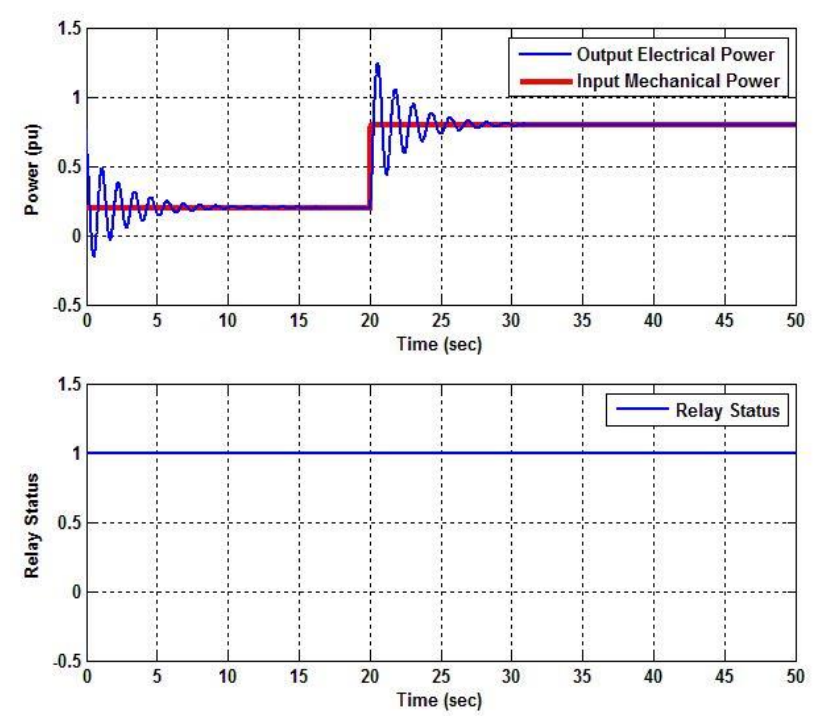

Fig 5. (a) Input/Output Power of the relay (b) Status of the relay

\section{CASE-2:}

Inside 90 seconds, the mechanical contribution to the generator fluctuates from 0.5 to $0.1 \mathrm{pu}$. in the subsequent model. Figure 6 (a) shows the deliberate information/yield power and (b)relay state. The hand-off doesn't trip in this situation. The electrical $\mathrm{o} / \mathrm{p}$, in any case, momentarily switches $(-0.2 \mathrm{pu})$ at 90 seconds. This is one more illustration of a steady framework.
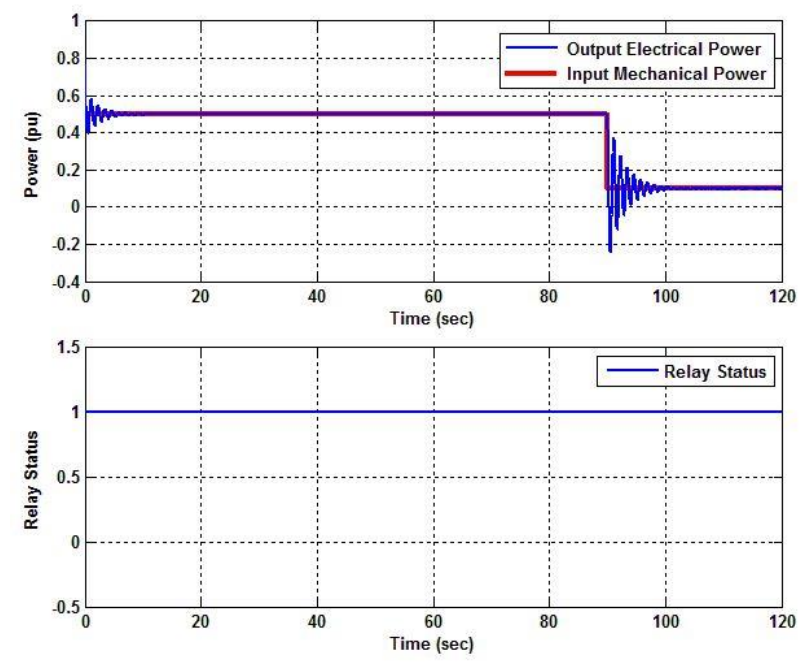

Fig 6. (a) Input/Output Power of the relay (b) Status of the relay

CASE-3:

Inside 90 seconds, the mechanical contribution to the generator goes from 0.5 to $-0.1 \mathrm{pu}$. Figure 7 (a)depicts the noticed information/yield power and (b)relay state. It tends to be seen that the hand-off 
trips around 7 seconds after the shortcoming happens at 90 seconds.
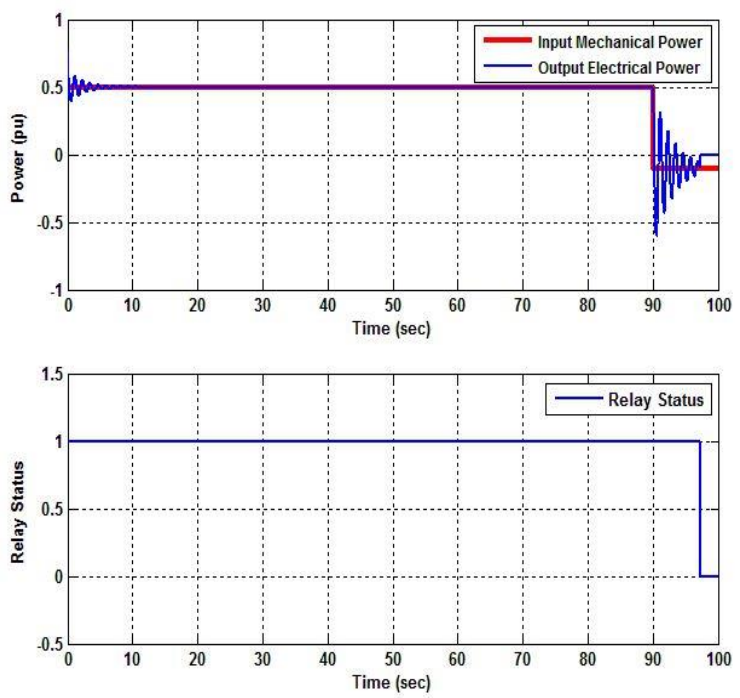

Fig 7. (a) Input/Output Power of the relay (b) Status of the relay

\section{CASE-4:}

Fourth case is an aggregate case that exhibits the opposite power hand-off's presentation under different circumstances. From 0 to 140 seconds, the mechanical contribution to the generator fluctuates ordinarily. During every mechanical transient, the framework works securely, and the generator is safely segregated at 107 seconds, when mechanical $\mathrm{I} / \mathrm{p}$ misfortune happens, as displayed in Fig. 8. Figure 8 (a)depicts the noticed information/yield power and (b)relay state.
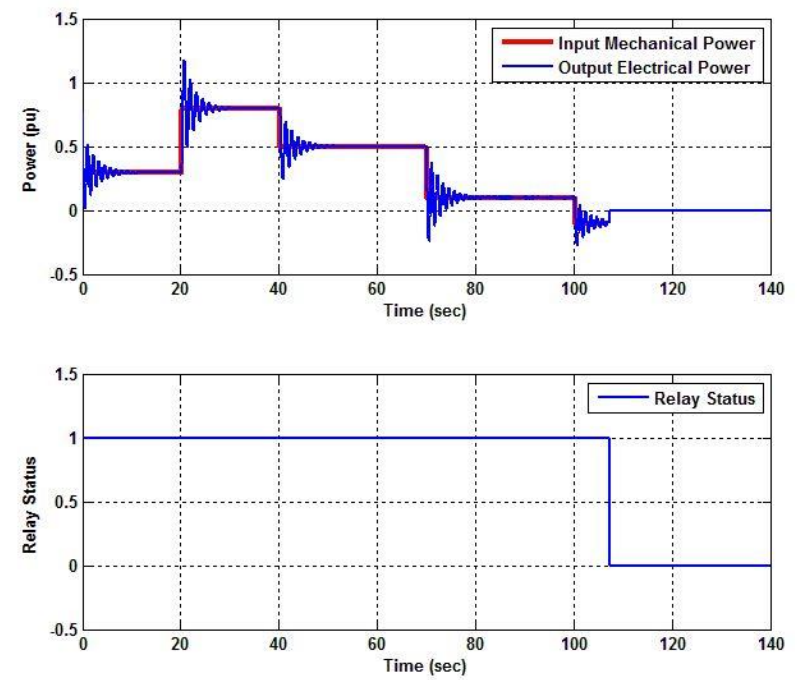

Fig 8. (a) Input/Output Power of the relay (b) Status of the relay

This paper aimed to present a digital reverse model which is cost effective and also provides a greater flexibility while maintaining the overall system performance. The mechanical input to the system has been varied within a range of magnitudes and time and the respective results are obtained. The results are then compared with the respective simulations and the physical frameworks found in the text.

\section{Conclusion}

The demonstrating and reenactment of advanced opposite power transfers utilizing MATLAB were portrayed in this work. Various instances have been used as case studies to show the suggested relay concept The digitizing system is additionally completely portrayed. In contrast with other power hand-off models in existing power framework programming, MATLAB gives a critical benefit as far as adaptability. Specialists may change the testing settings and the transfer's plan. RPR can shield the generator against the effects of opposite power prompted by a disappointment of the power plant's essential drive. The defect is caused by instabilities, which reduces the generator's output power, leading the generator to modify its function. It can read the change in the direction of the generator output with the aid of RPR by resetting the RPR to the generator. According to the IEEE standard, the maximum return value is $-12.66 \mathrm{MW}$, which is equal to $50 \%$. The simulation results revealed a high percentage of turning power of $6 \%$, which is within the IEEE standard range. The RPR delay time is currently set at 0.2 seconds (IEEE is 30 seconds). The delay time is 0.2 seconds, which is comparable to 0.6 percent. The RPR settings put on the generator must then conform to the IEEE C37.102-2006 standard. With a 50 percent to 95 percent modification percentage of the installed parameters, RPR adjustment can shorten the relay delay time. The findings of the study can help to improve generator protection and reduce the effect of internal or external faults. It's additionally important that speedier working of this transfer can diminish the generator's driving time, mechanical weight on the turbine and blower shaft, and, subsequently, the main player's related dangers.

\subsection{Future Scope}

In this paper, the mechanical input to the system has been played with an array of different magnitudes and time. The simulation presented in the paper can influence the physical framework of the entire system and hence, can be used to determine an optimal solution to the given problem. The mechanical input to the system can further be varied within a greater range of magnitudes and time values to find a more optimized solution. 


\section{References:}

[1] Yaghobi. H., et al., "Out-of-step protection of generator using analysis of angular velocity and acceleration data measured from magnetic flux," Electr. Power Syst. Res., vol. 132, pp. 9-21, 2016.

[2] Lukač. M. and Matišić Z, " Anti-islanding protection of distributed generators with regard to sensitivity in a balance and power system stability," CIREDOpen Access Proc. J., pp. 943946, 2017.

[3] Razzaghi. R., Davarpanah M. and SanayePasand M., " A novel protective scheme to protect small-scale synchronous generators against transient instability," IEEE Trans. Ind. Electron., Vol. 60, pp. 1659-1667, 2013.

[4] Abdel Aziz M., Elsamahy Bendary M., Moustafa Hassan M.A., " A novel study for hydrogenerators loss of excitation faults detection using ANFIS," Int. J. Model. Simul., Vol. 37, pp. 36-45, 2017.

[5] Rahman S.A., Moghaddami H. and Sarwat M., "Reverse power flow protection in grid connected PV systems", IEEE SoutheastCon, April 2018.

[6] Nuzzo S., Galea M. and Gerada C., "Analysis, modeling, and design considerations for the excitation systems of synchronous generators", IEEE Trans. Ind. Electron., Vol. 65, pp. 29963007, 2018.

[7] Sudhakar P.M. and Sushama Sarvesh B, "Reducing the impact of DG on distribution networks protection with reverse power relay", Mater. Today: Proc., Vol. 5, pp. 51-57, 2018.

[8] Aman. M., Jasmon G., Khan Q., "Modeling and simulation of reverse power relay for generator protection", IEEE Int. Power Engineering and Optimization Conf. (PEDCO), pp. 317-322, June 2012.

[9] Klempner G. and Kerszenbaum I., "Operation and maintenance of large turbogenerators", John Wiley \& Sons, Hoboken, vol. 14, 2004.

[10] Clark H.K. and Feltes, J.W., "Industrial and cogeneration protection problems requiring simulation", IEEE Trans. Ind. Appl., Vol. 25, pp. 766-775, 1989.
[11] Jenkins A., Duncan J. and Lynch C.A., "Impact of steam turbine valve closure on a synchronous machine and its reverse power protection", Proc. of 12th IET Int. Conf. on Developments in Power System Protection (DPSP), pp. 1-6, 2014.

[12] Nichols W.H. and Castro C.A., "Power system phase rotation and polarized protective relays", IEEE Trans. Ind. Appl., Vol. 26, pp. 1075-1080, Nov - Dec 1990.

[13] Yaghobi H., et al, "Fast predictive technique for reverse power detection in synchronous generator", IET Electr. Power Appl., Vol. 12, pp. 508-517, 2018.

[14] Yaghobi H., et al, "A new adaptive impedancebased LOE protection of synchronous generator in the presence of STATCOM", IEEE Trans. Power Deliv., Vol. 32, pp. 2489-2499, 2017.

[15] Mahamedi, B., Zhu J. G. and Hashemi S.M., "A setting-free approach to detecting loss of excitation in synchronous generators", IEEE Trans. Power Deliv., Vol. 31, pp. 2270-2278, Dec 2015.

[16] Ostojić M. and Djurić M., "The algorithm for the detection of loss of excitation of synchronous generators based on a digital-phase comparator", Electr. Eng., Vol.100, pp. 1287-1296, 2018.

[17] Hasani A. and Haghjoo F., "A secure and settingfree technique to detect loss of field in synchronous generators", IEEE Trans. Energy Convers., Vol. 32, pp. 1512-1522, 2017.

[18] Hasani A. and Haghjoo, F., "Fast and secure detection technique for loss of field occurrence in synchronous generators", IET Electr. Power Appl., Vol. 11, pp. 567-57, 2017.

[19] K. Wannous and P. Toman, "Evaluation of Harmonics Impact on Digital Relays," Energies, vol. 11, no. 4, pp. 893, Apr. 2018.

[20] Ernesto Vázquez M, Alejandro Zamora-Mendez, Mario R. Arrieta Paternina, Luis A. TrujilloGuajardo, Jose A. de la O Serna, "Dynamic phasor-driven digital distance relays protection," Vol. 184, 2020.

[21] S. H. K. Hamadi et al., "Modelling of partial discharge signal and noise interference using LabVIEW," IEEE 15th Student Conference on Research and Development (SCOReD), pp. 451455, 2017. 
[22] A. Lei, X. Dong and V. Terzija, "An Ultra-HighSpeed Directional Relay Based on Correlation of Incremental Quantities," in IEEE Transactions on Power Delivery, vol. 33, no. 6, pp. 2726-2735, Dec. 2018.

[23] J. P. Holguin, D. C. Rodriguez and G. Ramos, "Reverse Power Flow (RPF) Detection and Impact on Protection Coordination of Distribution Systems," in IEEE Transactions on Industry Applications, vol. 56, no. 3, pp. 23932401, May-June 2020.

[24] A. A. Balyith, H. M. Sharaf, M. Shaaban, E. F. El-Saadany and H. H. Zeineldin, "NonCommunication Based Time-Current-Voltage Dual Setting Directional Overcurrent Protection for Radial Distribution Systems With DG," in IEEE Access, vol. 8, pp. 190572-190581, 2020.

[25] M. M. Aman, Ghauth Bin Jasmon, Qadeer Ahmed Khan, A. Halim Bin Abu Bakar and Jasrul Jamani Jamian, "Modeling and simulation of reverse power relay for generator protection," 2012 IEEE International Power Engineering and Optimization Conference Melaka, pp. 317-322, 2012.

[26] B. Agheli, A. Kalami and A. Amini, "Design of an Overcurrent Protection Relay Based on Electronics Technology," 28th International Conference on Mixed Design of Integrated Circuits and System, pp. 211-216,2021.

[27] L. Hong, M. Rizwan, M. Wasif, S. Ahmad, M. Zaindin and M. Firdausi, "User-Defined Dual Setting Directional Overcurrent Relays with Hybrid Time Current-Voltage CharacteristicsBased Protection Coordination for Active Distribution Network," in IEEE Access, vol. 9, pp. 62752-62769, 2021.

[28] S. -H. Lim and M. -K. Park, "Analysis on Protection Coordination of OCRs Using Voltage Components for the Application of SFCL in a Power Distribution System with DG," in IEEE Transactions on Applied Superconductivity, vol. 31, no. 5, pp. 1-6, Aug. 2021.

[29] S. Biswal, M. Biswal and O. P. Malik, "Hilbert Huang Transform Based Online Differential Relay Algorithm for a Shunt-Compensated Transmission Line," in IEEE Transactions on Power Delivery, vol. 33, no. 6, pp. 2803-2811, Dec. 2018.
[30] D. Paul, et al, "Phase-Ground Fault Current Analysis and Protection of a High-Resistance Grounded Power System," in IEEE Transactions on Industry Applications, vol. 56, no. 4, pp. 3306-3314, July-Aug. 2020.

\section{Contribution of individual authors to the creation of a scientific article (ghostwriting policy)}

Ananya Aprameya, Suman Patra went through various research works in the past to figure out the existing and possible solution to the problem, and wrote Section 2: Literature Survey.

Suman Patra worked upon the sections like Problem Formulation and Problem Solution.

Suman Patra, Bimalendu Mishra carried out several simulations and found their results, which are mentioned in Section 5: Simulation and Results.

Bimalendu Mishra, Ananya Aprameya went through the current research methodology and tried to optimize the algorithms based on the result of simulations.

\section{Creative Commons Attribution License 4.0 (Attribution 4.0 International, CC BY 4.0)}

This article is published under the terms of the Creative Commons Attribution License 4.0 https://creativecommons.org/licenses/by/4.0/deed.en US 